\title{
Impact of urban green space attribute on visitors' satisfaction in Putrajaya: Malaysia
}

\begin{abstract}
Systematic distribution and management strategy of urban green spaces has proved to have positive impact (positively influenced) on aesthetic features of urban environment. This translated into greater neighbourhood and visitors' improved overall satisfaction. However, on the contrary, this manifests to affect the natural features of the urban environment, leading to non-negligible dissatisfaction. Careful consideration of green space is judged based on their particular necessity in terms of quality and service provision towards the desirable development of Putrajaya. In this study, 386 samples are considered based on Krejcie and Morgan 1970 sample size formula. The results obtained indicated a strong positive relationship between urban green space attributes and satisfaction. Whereas, results of regression analysis shows that the entire predicting variables have significant unique contribution in determining satisfaction to urban green spaces visitors' in Putrajaya.
\end{abstract}

Keyword: Urban green space; Quality; Quantity; Accessibility; Satisfaction; Putrajaya; Malaysia 